\title{
Diálogos cruzados: conversas e experiências em Políticas de Ações Afirmativas e Direitos Coletivos na universidade
}

\author{
PATRICIA CARVALHO ROSA
}

RAFAEL PACHECO

Em 11 maio de 2016, o Ministério da Educação emitiu a Portaria Normativa $n^{\circ} 13^{1}$, a qual determinava o prazo de 90 dias para que as Instituições Federais de Ensino Superior (IFES) apresentassem propostas sobre a inclusão de estudantes direcionadas aos grupos minoritários, tais como negros (pretos e pardos), indígenas, quilombolas, pessoas com deficiências, pessoas transgênero e estudantes oriundos de escolas públicas nos seus programas de pós-graduação. A Portaria é fruto de um conjunto de debates prévios levados a cabo no grupo de trabalho instituído em 2015 pelo MEC (Portaria ${ }^{\circ}$ 929/2015²), em consonância com o documento CAPES no $149 / 2015^{3}$, que criou o grupo de trabalho designado a realizar diagnósticos da pós-graduação brasileira, encerrando-se suas atividades em 13 de maio de $2016^{4}$.

1 Diário Oficial da União. https://www.capes.gov.br/images/stories/download/legislacao/12052016-PORTARIA-NORMATIVA-13-DE-11-DE-MAIO-DE-2016-E-PORTARIA-N-396-DE-10-DE-MAIO-DE-2016.pdf

2 https://www.capes.gov.br/images/stories/download/legislacao/1592015-PORTARIA-No-929-DE-14-DE-SETEMBRO-

-DE-2015.pdf

3 https://capes.gov.br/images/stories/download/avaliacao/avaliacao-n/Portaria-capes-90-91-2015.pdf

4 Portaria CPES n 66. https://www.capes.gov.br/images/stories/download/legislacao/13052016-PORTARIA-N-66-de-12-05-2016. pdf> acesso em janeiro de 2018 . 
O novo instrumento normativo reacendeu o debate em diferentes frentes, reabrindo espaços de interlocução, na academia e nos movimentos sociais, ao mesmo tempo em que mobilizações e proposições protagonizados por coletivos de estudantes e docentes, indígenas, de negras e negros e quilombolas em diversas universidades incitaram novas perspectivas acerca das políticas afirmativas. Veja-se, por exemplo, o dossiê "Ações afirmativas nos programas de pós-graduação em Antropologia”, publicado pela Revista de Antropologia (v. 60, n.1) em 2017. É nesse sentido que por meio deste dossiê a Campos se soma a este movimento (auto) reflexivo, na expectativa e na certeza de que outras - e novas - contribuições possam qualificar ainda mais este debate.

Em meados de setembro do mesmo ano, por ocasião da realização da VIII Semana de Antropologia e Arqueologia, evento anual realizado pelo Programa de Pós-Graduação em Antropologia (PPGA) da UFPR, a comissão organizadora, composta por docentes e discentes do Departamento (DEAN) e do PPGA, decidiu pela criação de um espaço na programação dedicado às discussões sobre as Políticas de Ações Afirmativas (PPAs) e Direitos Coletivos. Tal iniciativa, inserida nos debates internos já em curso no DEAN e no PPGA, configurou-se, de certo modo, a partir do interesse pelo tema exposto por alguns membros da organização do evento, dentre os quais estava eu, docente àquela altura no Departamento de Antropologia, e o mestrando Rafael Pacheco, à época representante discente na casa e um dos proponentes do dossiê que se segue.

Juntamente aos colegas, pautávamos, no âmbito daquela comissão, que a existência de um espaço ao debate mostrava-se importante na medida em que o próprio PPGA vivenciava a elaboração dos primeiros editais com reservas de vagas a candidatos autodeclarados negros, indígenas e quilombolas, motivo pelo qual sugerimos reunir no evento, de largo alcance como é a Semana de Antropologia e Arqueologia, estudantes cotistas e docentes da própria universidade - uma das instituições pioneiras a adotar políticas afirmativas na graduação - para somarem suas experiências diferenciadas àquelas de pessoas convidadas de outras instituições, algumas das quais com as PAAs já implementados na graduação e pós graduação. O que estava sendo pautado ali, deve-se sublinhar, era menos um exame das políticas e posições mais gerais da UFPR ou do PPGA, mas antes, a criação de um momento de participação de agentes diversos, situados em diferentes perspectivas nesta rede e com engajamentos distintos nestes processos.

Para tanto, partíamos do questionamento seguinte: o que se pode aprender através da escuta dos estudantes cotistas e de docentes, que direta ou indiretamente haviam acompanhado o processo de implementação ou de convivência com as PAAs, e desse modo, conhecer dimensões propositivas para o enfrentamento dos desafios e tensões de sua gestão, na UFPR e em outros contextos institucionais? Optamos por escutar experiências diversas, plurais e multissituadas relativas aos efeitos da presença das alteridades na universidade, notadamente ouvindo-as falar dos impactos das políticas de inclusão. A partir disso, pudemos debater as políticas institucionais considerando elementos como a interculturalidade e os diferentes entendimentos acerca dos processos de ensino-aprendizagem que estão diretamente conectados às incitações referentes ao ingresso dessas alteridades, sua permanência e formação. Buscávamos, por fim, incentivos múltiplos - políticos, epistemológicos e institucionais - para seguir caminhando. 
Assim, para que o espaço no evento existisse, bem como este dossiê que dele resultou e aqui apresentamos, contamos com o apoio do professor do PPGA, Marcos Silva da Silveira, então chefe do DEAN, especialista e atuante nesta área, e autor neste dossiê. Elaboramos a proposta da mesa redonda e o passo seguinte foi consultar alguns estudantes cotistas da graduação, quilombolas do Programa Nacional de Educação na Reforma Agrária (PRONERA) e indígenas do Programa de Educação Tutorial (PET) Conexões de Saberes, popularmente designado "PET Indígena", bem como alguns discentes negro/as, componentes do Núcleo de Estudos Afro-Brasileiros (NEAB). Além de convidá-los para compor o debate, era preciso conhecer suas sugestões. E deles partiu a ideia de organizar a discussão como uma roda de conversa, privilegiando relatos de experiências, e menos no formato de mesa redonda, entendida como demasiado formal e mais adequada a relatos de pesquisa ou análises mais gerais das políticas, portanto, pouco estimulante para a exposição e partilha de experiências na forma de relatos. Partindo dessa construção a muitas mãos, ocorria à noite do dia 21 de setembro, no anfiteatro 800 do edifício D. Pedro I, no campus da Reitoria da UFPR, a atividade chamada Diálogos cruzados: conversas e experiências sobre Açôes Afirmativas e Direitos Coletivos na universidade.

A audiência, composta de público diverso, ouvia às palavras de Jeferson Pereira, quilombola e acadêmico de Direito vinculado ao NEAB e dos professores da casa Eduardo Harder, do Setor Litoral e coordenador do PET Litoral Indígena, e Marcos Silva da Silva, do PPGA. Além deles, contamos também com as contribuições trazidas por duas convidadas externas, Joziléia Jagso Inácio Jacodsen, indígena Kaingang, coordenadora pedagógica da Licenciatura Intercultural Indígena do Sul da Mata Atlântica (UFSC) e doutoranda do Programa de Pós-Graduação em Memória Social e Patrimônio Cultural (UFPEL), e Marcela Coelho de Souza, antropóloga e docente no Departamento de Antropologia da Universidade de Brasília (UnB).

Com vistas a amplificar a circulação do debate promovido, a Campos abriu uma seção editorial para que pudéssemos publicizá-lo e o resultado é o dossiê que se apresenta a seguir, contendo parte dos diálogos derivados do evento. Tratam-se de leituras feitas por especialistas, estudantes, docentes e militantes com envolvimento na implementação, gestão, acompanhamento e crítica das PAAs. Ao lê-las, entenderemos que se as experiências aqui relatadas são particulares, provenientes de contextos institucionais variados, seus efeitos hospedam problemática comum, para além daquela já amplamente observada nas análises realizadas do enfretamento dos "racismos institucionais" ( $C f$. Cohn e Lourenço neste dossiê) e muitas vezes dimensionada à subalternização das formas em que, em especial, as alteridades indígenas e negras e se expressam no imaginário colonial. Os relatos aqui coligidos coadunam excertos sobre o que se conversou naquela roda de conversa, focalizando questóes étnico-raciais no contexto da universitário a partir daquilo que Cohn nos descreve como o "duplo reconhecimento": não basta reconhecer a presença das alteridades indígenas ou negras ou quilombolas na universidade, abrigando formalmente suas formas de agências e demandas, sem que suas reivindicações diferenciadas associadas aos processos institucionais de ensino-aprendizagem sejam também realizadas nas práticas de ensino, pesquisa e extensão. Nesse sentido, com o material aqui apresentado, pretende-se, de um lado, compartilhar a experiência da UFPR, e de outro, colocá-la em relação com outras experiências, potencializando ainda mais os cruzamentos de ideias. De um modo geral, todos os textos abarcam os 
desafios colocados pela implementação e gestão de PAAs não encerrando seus limites no problema das dificuldades advindas da linguagem e do funcionamento burocrático, ou das adaptações a um universo urbano. Ao mesmo tempo crítico e celebrativo, os aportes que se seguem abrangem dimensões intersubjetivas e afetivas, além da pedagógica, relativas às presenças indígena, negra e quilombola nas salas de aula e demais espaços acadêmicos.

Afetações políticas, identitárias e epistemológicas de diferentes ordens e naturezas estão presentes nestes textos, proporcionando a quem os lê um panorama instigante à reflexão. O que implica ser negra, indígena ou quilombola num contexto universitário? Desejos, expectativas, medos, sofrimentos e saberes diferenciados, autoconhecimento, socialidades genderizadas, redes de relações e temporalidades são expostas pelos autores como elementos relevantes para nossas tentativas de compreensão dos muitos significados que os PAAs provocam na universidade, considerando-se aí também uma crítica de como ela lida com questões étnico-racial.

Há, nessas ações, muitas conquistas; restam, ainda, inúmeros desafios. De uma perspectiva "de dentro", das próprias experiências discentes, muitas noções colonizadoras a respeito de suas próprias condições de existências poderão ser desmistificadas, pontuam os autores. Conhecer os sentidos e modos que as/os estudantis da experiência universitária, e reconhecê-los plenamente ainda são desafios que impedem as possibilidades de uma vivência intelectual, política e acadêmica mais simétrica.

Clarice Cohn, no texto que abre este dossiê, Uma década de presença indigena na UFSCAr, destaca, desde suas experiências naquela universidade, a necessidade político-epistemológica de romper com as heranças de uma pedagogia cartesiana e reducionista que oferecem resistências à interculturalidade e à compreensão de distintas temporalidades também no que se refere à incorporação de saberes, enfatizando a relação coextensiva entre conhecimentos, corpos e formas de habitar o mundo. O alcance da horizontalidade das atuações políticas e acadêmicas de indígenas e não indígenas é apontado por Cohn como um dos desafios da implementação das PAAs.

Na sequência, o texto de Sônia Regina Lourenço, Ações Afrrmativas para Estudantes Quilombolas: o processo de criação do Programa de Inclusão de Estudantes Quilombolas (PROINQ) na Universidade Federal do Mato Grosso, relata a experiência da criação do Programa como um processo constituído com intensa pluralidade de atores, destacando participação dos atores do movimento social local e da academia. Na esteira da discussão do artigo anterior, Sônia nos relata a experiência da UFMT lançando mão de uma miríade de outros relatos, de diversos atores implicados, com destaque aos quilombolas, que indicavam a necessidade de ampliar e complexificar a discussão sobre historicidades negras e etnicidade que caracterizam mas "não encerram" as organizações quilombolas e seus modos de conhecimentos num passado estanque e colonial, oferecendo-nos, assim, um importante debate analítico relativo às categorias sociais de "negro" e "quilombolas", entre outras, circunscritas nos debates clássicos e contemporâneos das temáticas étnico-raciais no discurso antropológico brasileiro. De modo fluido e provocativo, a autora argumenta no sentido da necessidade de as políticas públicas para a educação quanto ao "reconhecimento de que a sociedade brasileira é pluriétnica" e, ademais, que "o direito à igualdade não prescinde do direito à diferença”. 
O debate sobre as categorias de escrutínio em discursos multissituados continua sendo levado à frente no artigo de Marcos Silva da Silveira, Algumas questóes antropológicas a partir do Programa de Inclusão racial da Universidade Federal do Paraná, tratando dos entendimentos da categoria "pardo", configurada e mobilizada na política acadêmica, nas mídias e no debate sobre política afirmativas. O texto é reflexo de questionamentos emergidos em seu pós-doutoramento junto ao Laboratório de Pesquisas em Etnicidade, Cultura e Desenvolvimento (LACED) do Museu Nacional, dimensionado por sua etnografia das bancas de verificação de autodeclaração étnico-racial na UFPR, bem como suas alterações a partir de 2013 induzidas pela lei federal de cotas. O exercício analítico operado por Silveira parte da ideia de que a categoria pardo "não define", e o panorama acerca dela no interior da disciplina é conectado aos de outras arenas de discussão e deliberação sobre as políticas inclusivas, convidando-nos a pensar com ele sobre a problemática central, como segue:

\footnotetext{
"se esta categoria não define o pertencimento a um grupo social específico, seja racial, étnico, religioso ou regional, como lidar com ela quando se precisa definir se um cidadão faz juz a uma política pública inclusiva, voltada para um público alvo, que precisa, ser validade de alguma forma, tomando-a como referência?"
}

Ana Caroline Goulart, na sequência, descreve e reflete sobre os "diferentes modos de se relacionar" com a universidade indicadas pelas heterogeneidades e "curvas" dos trajetos acadêmicos de estudantes indígenas kaingang e guarani na Universidade Estadual de Londrina (UEL), no norte do Paraná. As perspectivas estudantis sobre as políticas inclusivas propriamente, bem como as implicações desta em seus desejos profissionais, são tomadas pela autora de Caminho de ida e de volta: temporalidade e projetos entre acadêmicos Kaingan e Guarani na Universidade Estadual de Londrina, conduzindo-nos pelos trajetos de acadêmicos indígenas, mostrando tratarem-se de percursos marcados por heterogeneidades e "curvas". Retomando as provocações lançadas por Clarice Cohn e Sônia Lourenço acerca do desafio de permanecer na universidade, demonstrando que ali no norte do Paraná, a permanência e a construção de um projeto de formação superior não se restringem apenas à/ao estudante, mas também às suas redes familiares e lideranças. Em termos de temporalidade - "as experiências por trás do tempo" -, distinguidos um tempo instituído (regularmente previsto) e um "tempo vivido", Caroline aponta que além das redes de relações, o "encontro com si" constitui também um dos fatores diretamente associados ao tempo de permanência na graduação.

O dossiê encerra-se com o ensaio de Lays Gonçalves da Silva, Povos Indígenas no contexto do ensino superior: desafios do acesso e da permanência na Universidade Federal do Paraná, produzido a partir da reflexão incipiente, ainda em curso, sobre a presença indígena na universidade. Para isso, a autora foca as experiências plurais de estudantes que ingressaram nos cursos do Setor Ciências da Saúde da UFPR por meio do Vestibular Interinstitucional dos Povos Indígenas do Estado do Paraná, o "Vestibular Indígena”. Com isso, Lays traça uma compreensão geral do processo de institucionalização da política de escolarização diferenciada para povos indígenas no ensino superior do Brasil desde este 
caso particular. Considerando elementos tais quais a chegada à cidade, o acolhimento na universidade, a garantia de existência na instituição e de seus regimes de saberes como elementos também formativos, além de questões de ordem mais burocrática, são suplementados os questionamentos dos textos precedentes, finalizando este dossiê com a retomada de um conjunto de questionamentos, para que sigamos na reflexão.

Boa leitura!

Patricia Carvalho Rosa é doutora em Antropologia pela UNICAMP e Pesquisadora Titular no Instituto de Pesquisa Mamirauá

Rafael Pacheco é graduado em Ciências Sociais pela Universidade de São Paulo (USP) e mestrando em Antropologia no PPGA/UFPR 